\title{
The Effects of Subacute Supraphysiological Dose of Nandrolone Decanoate on Liver Enzymes and Lipid Pofiles in Rats
}

\author{
Mohammad Reza Shahraki ${ }^{1, *}$ and Roya Rafeei ${ }^{2}$ \\ ${ }^{1}$ Department of Physiology, Zahedan University of Medical Sciences, Zahedan, IR Iran \\ ${ }^{2}$ Saravan Health Center, Zahedan University of Medical Sciences, Zahedan, IR Iran \\ ${ }^{*}$ Corresponding author: Mohammad Reza Shahraki, Saravan Health Center, Zahedan University of Medical Sciences, Zahedan, IR Iran. E-mail: m_shahrakim@zaums.ac.ir \\ Received: January 25, 2014; Accepted: April 25, 2014
}

\begin{abstract}
Background: Nandrolone decanoate (ND) is a doping agent which is used by athletes and has a lot of adverse effects on the body. Objectives: This survey was carried out to evaluate the effects of subacute supraphysiological dose of NDadministration on liver enzymes and lipid profiles in male and female rats.

Materials and Methods: This experimental study was performed on 40 Wistar-Albino rats, which after weighing divided into 4 groups as control (female and male) and test (female and male) groups $(\mathrm{N}=10)$. The test groups received $15 \mathrm{mg} / \mathrm{kg}$ nandrolone decanoate by intra muscular (im) injection for 2 weeks, but control groups received the same volum of oil vehicle. At the end, animals were deeply anesthetized by diethyl ether, scarified and their blood samples were collected. Liver enzymes and lipoproteins were measured by usual methods. Obtained data were analyzed by SPSS-15, applying ANOVA and Tukey tests. Results were expressed as mean \pm SD. Statistical difference was recognized significant by $P \leq 0.05$.

Results: Results showed that AST value in the test groups were significantly increased compared to those of the control groups. In addition, HDL and cholesterol values in female test group were significantly increased compared to those of male test group. Moreover, final weight, food, and water intake in all test groups were significantly increased compared to those of control groups.

Conclusions: These results indicated that subacute administration of nandrolone decanoate alters liver enzymes, lipoprotein profile, final weight, food, and water intake in rats. The exact mechanism needs future studies.
\end{abstract}

Keywords: Nandrolone; Lipoprotein; Rat; Liver enzyme; Blood sugar

\section{Background}

Anabolic androgen steroids (AAS) such as nanderlone decaneate (ND) are used in athletes to enhance their muscular performance, body weight, fighting and physical potency [ 1 , 2]. The long-term AAS use seems to modify body foundation, muscle physique and reduce fat mass in athletes [3]. In addition, ND is used to treat anemia in patients on hemodialysis [4-6]. Assessment exposed that an extended management of AAS remains a series injures in different organs, particularly, in liver, and causes elevation of the liver enzymes [7]. Lesna and Taylor showed that anabolic androgen steroids caused the hepatoxicity in mice with and without pretreatment with diethylnitrosamine enhanced [8]. On the other hand, administration of ND causes the increase of the glutathione-s-transferases enzyme activity in mice [9]. In patients who were treated with ND the serum levels of cholesterol and triglyceride were increased unlike the high-density lipoprotein concentration which was decreased compared with that on the control groups [10, 11]. Kafrouni et al. pronounced that AAS are being sold as dietary supplements and are still the main cause of hepatotoxicity in the United States [12]. Our serach gives evidence for wide ranging effects of AAS on the hypothalamic-pituitary-adrenal axis and adipose tissue [13,14]. Unlike the above report, some studies have shown that ND causes the liver regeneration enhances faster in rats after partial hepatectomy [15] but Alberti-Flor et al. showed that the use of synthetic anabolic androgen causes focal nodular hyperplasia in rats [16].

\section{Objectives}

Based on the above report, the aim of this survey was to evaluate the sub acute of ND supraphysiological dose administration on liver enzymes and serum lipid profiles in male and female rats.

\section{Materials and Methods}

This experimental study was performed on 40 mature male and female Wistar-Albino rats, pondering $180 \pm 30$ g; ages were 4 - 6 months which were separately housed in cages (one rat per cage). Animals had free access to water and food. Rats were sustained in a room at $23 \pm 2^{\circ} \mathrm{C}$ with a fixed 12 hour artificial light period (timer model: SUL180a, AC220V. China, 6 am to $6 \mathrm{pm}$ ), humidity of $45 \%-60 \%$ and the air was sufficiently recycled. 
All groups received ordinary rodent diet and tap water. After one week habituation, animals were divided into 4 male, female control, and test groups $(\mathrm{N}=10)$ as follow: Male and female test groups which received supraphysiological dose of ( $15 \mathrm{mg} / \mathrm{kg} \mathrm{im})$ ND daily for 2 weeks but male and female control groups received the same volume of peanut oil (oil vehicle) during the test period [17].

At first, there was no difference in weight among all the groups. ND was purchased from Caspian pharmaceutics collaboration and placed on appropriate temperature. Injection was performed between 8 - 10 am daily. At the end of experiment, rats were fasted for 14 - 16 hour [18], and sacrificed by cervical decapitation, under high dose of diethyl ether anesthesia. Blood samples were collected from cervical vein. High density lipoprotein (HDL), total cholesterol (TC) and triglyceride (TG) levels, serum AST (aspartate aminotransfrase), and ALT (alanine aminotransferase) were measured by standard methods adapted for a RA1000 analyzer (Technicon, USA). Low density li- poprotein (LDL) was calculated by Friedwald formula [19]. Obtained data were analyzed by SPSS-15. Variance analysis was used for comparison of the groups. Tukey test as a post hoc multiple comparison tests was used to compare healthy control and test groups. P value less than 0.05 was considered as significant.

\section{Results}

Our results showed that serum aspartate transaminase (AST) value in female and male test groups were significantly increased compared to those of female and male control groups (Tables 1 and 2), respectively. On the other hand, the results revealed that HDL value in female test group was significantly increased compared with that of male test group (Table 3). In addition, cholesterol value in female test group was significantly increased compared with that of male test group (Table 3). Furthermore, food and water intake and gain of weight in all test groups were significantly increased compared with those of control groups (Table 4).

Table 1. The Effects of Subacute Supraphysiological Dose of Nandrolone Decanoate on Liver Enzymes and Serum Lipid Profiles in Female Rats $\mathrm{a}, \mathrm{b}$

\begin{tabular}{lccccc}
\hline Groups & LDL $^{\mathrm{C}}$ & HDL $^{\mathrm{C}}$ & Cholestrol $^{\mathrm{C}}$ & TG $^{\mathrm{C}}$ & AST $^{\mathrm{d}}$ \\
\hline Control (A) & $6.7 \pm 3.8$ & $44.7 \pm 4.3$ & $64.8 \pm 13.8$ & $89.7 \pm 287$ & $164 \pm 41.1$ \\
Test (B) & $4.7 \pm 3.1$ & $47.7 \pm 7.4$ & $68.4 \pm 7.9$ & $85 \pm 20.6$ & $225 \pm 34.3$ \\
Pvalue & 0.9 & 0.4 & 0.8 & 0.6 & $63.4 \pm 15.73$ \\
\hline
\end{tabular}

a Based on student t-test: AST value in female test group B was significantly increased compared with that of control group A.

$\mathrm{b}$ Values are presented as mean $\pm \mathrm{SD}$.

c Values are based on $\mathrm{mg} / \mathrm{dL}$.

$\mathrm{d}$ Values are based on IU/L.

Table 2. The Effects of Subacute Supraphysiological Dose of Nandrolone Decanoate on Liver Enzymes and Serum Lipid Profiles in Male Rats ${ }^{a, b}$

\begin{tabular}{lccccc}
\hline Groups & LDL $^{\mathrm{C}}$ & HDL $^{\mathrm{C}}$ & Cholestrol $^{\mathrm{C}}$ & TG $^{\mathrm{C}}$ & AST $^{\mathrm{d}}$ \\
\hline Control (C) & $7.8 \pm 2.8$ & $43.7 \pm 10$ & $56.3 \pm 8.8$ & $82.6 \pm 23.6$ & $170.6 \pm 21.3$ \\
Test (D) & $8.5 \pm 3.1$ & $36.1 \pm 9.7$ & $54.4 \pm 12.6$ & $73.2 \pm 21.8$ & $250.9 \pm 38.9$ \\
Pvalue & 0.9 & 0.4 & 0.8 & 0.6 & $83.3 \pm 17.8$ \\
\hline
\end{tabular}

a Based on ANOVA and Tukey tests: AST value in male test group D was significantly increased compared with that of control group A.

$\mathrm{b}$ Values are presented as mean \pm SD.

c Values are based on $\mathrm{mg} / \mathrm{dL}$.

$\mathrm{d}$ Values are based on IU/L

Table 3. The Effects of Subacute Supraphysiological Dose of Nandrolone Decanoate on Liver Enzymes and Serum Lipid Profiles in Male and Female Test Groups a,b

\begin{tabular}{lccccc}
\hline Groups & LDL $^{\mathrm{C}}$ & HDL $^{\mathrm{C}}$ & Cholestrol $^{\mathrm{C}}$ & TG $^{\mathrm{C}}$ & AST $^{\mathrm{d}}$ \\
\hline Female test (B) & $4.7 \pm 3.1$ & $47.7 \pm 7.4$ & $68.4 \pm 7.9$ & $85 \pm 20.6$ & $225 \pm 41.3$ \\
Male test (D) & $3.5 \pm 2.1$ & $36.1 \pm 9.7$ & $54.4 \pm 12.6$ & $73.2 \pm 21.8$ & $250.9 \pm 38.9$ \\
Pvalue & 0.9 & 0.01 & 0.03 & 0.6 & $83.3 \pm 15.7$ \\
\hline
\end{tabular}

${ }^{\mathrm{a}}$ Based on student t-test: HDL and cholesterol values in male test group D was significantly decreased compared with those of female test group.

$\mathrm{b}$ Values are presented as mean \pm SD.

${ }^{\mathrm{C}}$ Values are based on $\mathrm{mg} / \mathrm{dL}$.

$\mathrm{d}$ Values are based on IU/L. 
Table 4. The Effects of Subacute Supraphysiological Dose of Nandrolone Decanoate on Gain of Weight, Water, and Food Intake in Male and Female Rats a,b

\begin{tabular}{|c|c|c|c|}
\hline Groups & Final Weight, g & Water Intake, mL & Food Intake, g \\
\hline Female control & $195.3 \pm 10.2$ & $60.3 \pm 11.2$ & $21.2 \pm 2.3$ \\
\hline Female & $212.1 \pm 9.7$ & $95.6 \pm 14.1$ & $24.8 \pm 1.9$ \\
\hline P value & 0.03 & 0.002 & 0.01 \\
\hline Male control & $194.5 \pm 11.4$ & $62.1 \pm 11.9$ & $22.4 \pm 2.9$ \\
\hline Male test & $214.6 \pm 12.1$ & $101.3 \pm 12.8$ & $25.6 \pm 2.1$ \\
\hline P value & 0.02 & 0.001 & 0.03 \\
\hline
\end{tabular}

\section{Discussion}

This study showed that subacute, supraphysiological dose of ND administration causes that AST value in male and female test groups were increased compared with those of male and female control group, but ALT value in all groups did not show any significant change. On the other hand, the results obtained from the present study expressed that cholesterol and HDL values in female test group were significantly higher than those of male test group. In addition of gaining weight, water, and food intake in male and female tests groups were significantly increased compared with those of male and female control groups. This section of our finding is accordance with those of Lindqvist and Fahlke which reported that ND-treated rats water consumption was significantly higher than those of control group [20]. Higher food and water intake in test groups may be due to ND cause alter metabolism in skeletal muscle and alteration in the excitation-contraction coupling mechanism [21]. Lindblom et al. reported that ND treatment affected on proopiomelanocorthin (POMC) production and affected food intake in rats [22].

Our results are accordance with those of van Amsterdam et al. which revealed that a prolonged of AAS administration irritates an increase in the activities of liver enzymes and increased risk for fatal liver cysts, other liver changes, and liver cancer [7]. Neri et al. [23] reported that a chronic administration of AAS induced an increase in the actions of liver lysosomal hydrolases and a decrease in some mechanism of the microsomal drug-metabolizing system. In addition, our results are in agreement with those of Acharjee et al. discovered that nandrolone decanoate is the most regularly injured anabolic steroid, which alter glutathiones-transferase enzyme activity in the live tissuse [24]. Our result is in agreement with those of Vieira et al. which considered that the nandrolone decanoate management leads to a dose-dependent increase in serum levels of the aspartate aminotransferase and alanine aminotransferase in male rats [25]. Our conclusion in the present study revealed that aspartate aminotransferase values just in the male and female test groups were increased compared to those of control groups but the amount of alanine aminotransferase value did not show any change between tests and control groups. These differences may be due to diverse methods or differences of the samples with other studies. Our finding has a consistency with those of Hartgens et al. revealed that in 19 subjects which had a self administration of AASs (ND) for 14 weeks, serum triglycerides and total cholesterol did not change with those of normal subjects [11]. Our results in the present study revealed that cholesterol and HDL values in female test group were significantly higher than those of male test group. This may be due to diverse sex hormone on male rats. This finding id in disagreement with those of Lippi et al. who discovered that total cholesterol and high density lipoprotein-cholesterol in 19 postmenopausal women who were given ND once a week for 3 weeks were significantly decreased compared to those of control group [26]. These differences may be due to different methods or treatment duration.

The results obtained from this experiment showed that ND sub acute, supraphysiological dose administration affected on liver enzymes and lipoprotein profile in male and female rats. However, the mechanism behind the action is yet unknown. The exact mechanism of these changes needs further studies.

\section{Acknowledgements}

This study was financially supported by the deputy of research at Zahedan university of Medical Sciences (project No: 793). We are grateful to Dr. Soroush Dabiri for their kind cooperation.

\section{Authors' Contributions}

All authors had equal role in design, work, statistical analysis and manuscript writing.

\section{Financial Disclosure}

The authors declare no conflict of interest. 


\section{Funding/Support}

This study was financially supported by the Deputy of Research at Zahedan University of Medical Sciences (project No: 793).

\section{References}

1. Hakansson A, Mickelsson K, Wallin C, Berglund M. Anabolic androgenic steroids in the general population: user characteristics and associations with substance use. Eur Addict Res. 2012;18(2):83-90.

2. Lippi G, Banfi G. Doping and thrombosis in sports. Semin Thromb Hemost. 2011;37(8):918-28.

3. Nordstrom A, Hogstrom G, Eriksson A, Bonnerud P, Tegner Y, Malm C. Higher muscle mass but lower gynoid fat mass in athletes using anabolic androgenic steroids. J Strength Cond Res. 2012;26(1):246-50.

4. Sheashaa H, Abdel-Razek W, El-Husseini A, Selim A, Hassan N, Abbas T, et al. Use of nandrolone decanoate as an adjuvant for erythropoietin dose reduction in treating anemia in patients on hemodialysis. Nephron Clin Pract. 2005;99(4):c102-6.

5. Deicher R, Horl WH. Hormonal adjuvants for the treatment of renal anaemia. Eur J Clin Invest. 2005;35 Suppl 3:75-84.

6. Lee MS, Ahn SH, Song JH. Effects of adjuvant androgen on anemia and nutritional parameters in chronic hemodialysis patients using low-dose recombinant human erythropoietin. Korean J Intern Med. 2002;17(3):167-73.

7. van Amsterdam J, Opperhuizen A, Hartgens F. Adverse health effects of anabolic-androgenic steroids. Regul Toxicol Pharmacol. 2010;57(1):117-23.

8. Lesna M, Taylor W. Liver lesions in BALB/C mice induced by an anabolic androgen (Decadurabolin), with and without pretreatment with diethylnitrosamine. J Steroid Biochem. 1986;24(1):449-53.

9. Acharjee BK, Mahanta R. Enhanced hepatic and kidney cytochrome p-450 activities in nandrolone decanoate treated albino mice. Drug Metab Lett. 2009;3(2):120-4.

10. Ghorbanihaghjo A, Argani H, Rohbaninoubar M, Rashtchizadeh N. Effect of Nandrolone Decanoate on serum lipoprotein (a) and its isoforms in hemodialysis patients. Lipids Health Dis. 2004;3:16.

11. Hartgens F, Rietjens G, Keizer HA, Kuipers H, Wolffenbuttel BH. Effects of androgenic-anabolic steroids on apolipoproteins and lipoprotein (a). BrJ Sports Med. 2004;38(3):253-9.

12. Kafrouni MI, Anders RA, Verma S. Hepatotoxicity associated with dietary supplements containing anabolic steroids. Clin Gastroenterol Hepatol. 2007;5(7):809-12.

13. Alsio J, Birgner C, Bjorkblom L, Isaksson P, Bergstrom L, Schioth $\mathrm{HB}$, et al. Impact of nandrolone decanoate on gene expression in endocrine systems related to the adverse effects of anabolic androgenic steroids. Basic Clin Pharmacol Toxicol. 2009;105(5):307-14.

14. Racca S, Piccione F, Spaccamiglio A, Carriero VM, De Francia S Cangemi L, et al. Effects of sub-chronic nandrolone administration on hormonal adaptive response to acute stress in rats. Psychoneuroendocrinology. 2012;37(8):1234-47.

15. Sileri P, Palmieri G, Gentileschi P, Perfetti A, Sica G, Venza M, et al. Anabolic steroid nandrolone augments hepatic regenerative response in rats. Transplant Proc. 2005;37(10):4563-6.

16. Alberti-Flor JJ, Iskandarani M, Jeffers L, Zeppa R, Schiff ER. Focal nodular hyperplasia associated with the use of a synthetic anabolic androgen. Am J Gastroenterol.1984;79(2):150-1.

17. Bissoli NS, Medeiros AR, Santos MC, Busato VC, Jarske RD, Abreu GR, et al. Long-term treatment with supraphysiological doses of nandrolone decanoate reduces the sensitivity of Bezold-Jarisch reflex control of heart rate and blood pressure. Pharmacol Res. 2009;59(6):379-84.

18. Rajasekaran S, Sivagnanam K, Subramanian S. Antioxidant effect of Aloe vera gel extract in streptozotocin-induced diabetes in rats. Pharmacol Rep. 2005;57(1):90-6.

19. Friedewald WT, Levy RI, Fredrickson DS. Estimation of the con centration of low-density lipoprotein cholesterol in plasma, without use of the preparative ultracentrifuge. Clin Chem. 1972;18(6):499-502.

20. Lindqvist AS, Fahlke C. Nandrolone decanoate has long-term effects on dominance in a competitive situation in male rats. Physiol Behav. 2005;84(1):45-51.

21. Joumaa WH, Leoty C. Differential effects of nandrolone decanoate in fast and slow rat skeletal muscles. Med Sci Sports Exerc. 2001;33(3):397-403.

22. Lindblom J, Kindlundh AM, Nyberg F, Bergstrom L, Wikberg JE. Anabolic androgenic steroid nandrolone decanoate reduces hypothalamic proopiomelanocortin mRNA levels. Brain Res. 2003;986(1-2):139-47.

23. Neri M, Bello S, Bonsignore A, Cantatore S, Riezzo I, Turillazzi E, et al. Anabolic androgenic steroids abuse and liver toxicity. Mini Rev Med Chem. 2011;11(5):430-7.

24. Acharjee BK, Mahanta R, Borkotoky A. Nandrolone decanoate enhances the activities of cholanthrene induced glutathiones-transferase in liver tissue of albino mice. Drug Metab Lett. 2010;4(1):1-6.

25. Vieira RP, Franca RF, Damaceno-Rodrigues NR, Dolhnikoff M, Caldini EG, Carvalho CR, et al. Dose-dependent hepatic response to subchronic administration of nandrolone decanoate. Med Sci Sports Exerc. 2008;40(5):842-7.

26. Lippi G, Guidi G, Ruzzenente O, Braga V, Adami S. Effects of nandrolone decanoate (Decadurabolin) on serum Lp(a), lipids and lipoproteins in women with postmenopausal osteoporosis. Scand J Clin Lab Invest. 1997;57(6):507-11. 